\title{
A CENTRIFUGAL PUMP SEALING METHOD BASED ON THE TRANSVERSE PRESSURE CONTROL
}

\author{
Liu Jie ${ }^{1}$, Huang Li Xin ${ }^{2}$ \\ ${ }^{1}$ Engineering training center, Shanghai University of Engineering Science, Shanghai, China \\ ${ }^{2}$ Engineering training center, Shanghai University of Engineering Science, Shanghai, China
}

\begin{abstract}
The efficiency of centrifugal pump is not high, and one of the reasons is improper seal leakage caused by the loss of the pump. The paper adopts a sealing method based on the transverse pressure control of centrifugal pump, to improve the sealing of the pump, and analyzes the relations between transverse pressure and other parameters, and the influence of each parameter to transverse pressure. After sealing design of centrifugal pump, its mechanical seal is improved greatly, and improve the efficiency of the centrifugal pump.
\end{abstract}

Keywords: Pump, Centrifugal pump, Transverse pressure, Mechanical seal.

\section{INTRODUCTION}

Pump is a kind of general fluid machinery, it is widely used in many parts of the national economy especially in water supply and drainage. Such as pumps and irrigation and drainage pumping station in against flood and drought disaster It is to improve agricultural production conditions, and with the rapid development of modern science and technology. And its application scope is expanding rapidly, and the working environment is becoming more and more complex, modern engineering technology to the performance demand is higher and higher, the traditional design method based on experience and combining the model test is difficult to meet the design requirements. Therefore, take advantage of the rapid development of CFD technology can be used to predict the performance of the centrifugal pump, and find out the factors that influence the performance of a centrifugal pump can make our innovation, and explore new design method.

At present, many problems exist in centrifugal pump seal improper, cause in the process of operation liquid leakage from pump or air into the pump, pump fluid flow, and there is a pressure difference between the atmosphere, and pump body gap between fluid along the axis outward leak, so you need to design reasonable sealing device.

Has important influence of specific pressure on seal face specific pressure will make the dry friction surface heating, increase the wear and power consumption increased at the same time, and end face specific pressure is too small, easy to leak and pollution, so want to have good sealing performance and enough life, to ensure the end face specific pressure in a suitable range, so the working efficiency of the pump will also increase.

\section{SEAL DESIGN OF CENTRIFUGAL PUMP}

\subsection{The Working Principle of Centrifugal Pump}

Although there are many types of centrifugal pumps, its working principle is the same, the main parts are impeller, pump shell, shaft, sealing device and bearing. See Fig. 1.

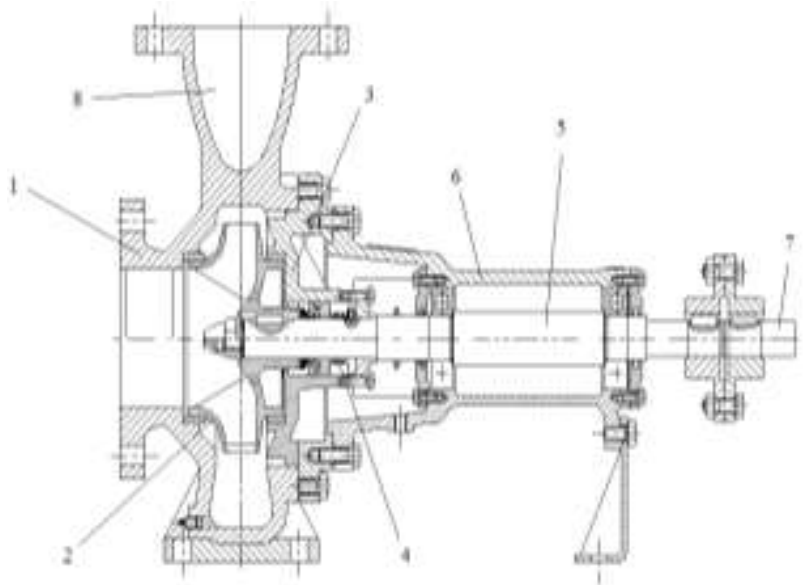

Fig 1: Assembly diagram of suspension centrifugal pump 1. pump body; 2 . impeller; 3 . pump cover; 4 . mechanical seal assembly; 5. pump shaft; 6. suspension; 7. coupling; 8. fluid outlet end

The working process of the centrifugal pump is actually a process of energy transfer and conversion, and the mechanical energy of the motor can be converted into the mechanical energy of the fluid.

Before starting the pump inside is full of liquid, under the drive of pump shaft, high-speed rotating impeller and generate centrifugal force of the water in the pump after being thrown, the center of the impeller of parts and the formation of vacuum suction side to form a certain pressure 
difference, under the action of pressure difference, fluid continuously flowing from suction pump impeller center, pump shaft constantly inhalation and discharged liquid to complete the movement of water. Before starting the centrifugal pump, the pump shell and the suction pipe must be filled with liquid, otherwise the pump shell will be hot and the "idling" phenomenon will occur, causing the equipment to be damaged.

According to the working principle of the centrifugal pump, the pressure of the liquid decreases gradually from the suction pipe to the suction inlet of the pump. When the pressure of a certain point in the pump is low and the vapor pressure of the liquid is saturated, some of the liquid will vaporize, and the resulting bubble is brought into the impeller by the liquid flow and the pressure in the impeller is broken. Due to the instantaneous vacuum generated by the condensation point, the surrounding liquid is subjected to high velocity impact, resulting in violent water strikes, which is called cavitation phenomenon.

Adverse consequences caused by cavitation:

(1) increased noise and vibration;

(2) performance degradation;

(3) the service life of the pump decreases.

Preventive measures: the centrifugal pump is installed at the appropriate height, so that the static pressure at the lowest point of the pump is greater than the saturated vapor pressure of the liquid at the working temperature.

For pump design, test and use, the cavitation margin is a very important basic parameter. The pump is designed according to the requirement of cavitation performance. If the user is given a specific requirement, the necessary cavitation margin must be less than the effective cavitation allowance determined by the conditions of use. In order to further improve the cavitation performance of the pump, the cavitation margin should be reduced.

The cavitation margin has the following relation:

$$
\mathrm{NPSH}_{\mathrm{C}}<N P S H_{\mathrm{r}}<[N P S H]<N P S H_{\mathrm{a}}
$$

By torma cavitation formula:

$$
\sigma=\frac{N P S H_{\mathrm{r}}}{\mathrm{H}}
$$

$\sigma$-toma cavitation coefficient;

$\mathrm{H}$-Pump maximum efficiency point under the single stage lift;

$\mathrm{NPSH}_{\mathrm{r}}--$ The cavitation margin at the highest efficiency point.

And $\sigma=0.075, N^{2} H_{\mathrm{r}}=\sigma \mathrm{H}=0.075 \times 40=3 \mathrm{~m}$.

\subsection{Mechanical Seal Design and Calculation}

\subsubsection{Face Pressure}

Face specific pressure has important effect on sealing situation, face specific pressure will make the dry friction surface heating, increase the wear and power consumption increased at the same time, and end face specific pressure is too small, easy to leak and pollution, so want to have good sealing performance and enough life, to ensure the end face specific pressure in a suitable range, so the working efficiency of the pump will also increase.

The principle of selecting the end face ratio pressure:

(1) The face pressure is greater than the pressure of the end face;

(2) The pressure is greater than the pressure of the liquid in the sealing gap;

(3) In the minimum leakage, the interstitial fluid film lubricates the friction surface.

Produced by elastic elements on the face of pressure, and sealing structure, medium type and pressure, to ensure that the sealing during the start and stop, compensation face wear and tear, spring should generate a certain amount of pressure.

For external loading, the spring ratio is $196 \sim 294 \mathrm{kPa}$.

\subsubsection{Calculate the End Face Ratio Pressure}

The ratio pressure of external mechanical seal:

$$
\begin{array}{r}
p=p_{l}+p_{j}\left(\mathrm{~K}_{\text {out }}-\lambda\right) \\
\mathrm{K}_{\text {out }}=\frac{\mathrm{d}^{2}-\mathrm{d}_{1}^{2}}{\mathrm{~d}_{2}^{2}-\mathrm{d}_{1}^{2}}
\end{array}
$$

Average pressure of the sealing ring contact surface:

$$
p_{\mathrm{m}}=\lambda p_{j}=0.7 \times 2.8 \mathrm{MPa}=2 \mathrm{MPa}
$$

Among them, the outer packing type mechanical seal $\lambda=0.7$

The thrust force of the contact section of the sealing ring:

$$
Q=p_{\mathrm{m}} \mathrm{A}=p_{m} \times \frac{\pi}{4}\left(d_{2}^{2}-d_{1}^{2}\right)=1447.6 \mathrm{~N}
$$

And $d_{2}=61.6 \mathrm{~mm}, d_{1}=53.6 \mathrm{~mm}, d=50 \mathrm{~mm}$,

$$
\mathrm{K}_{\mathrm{out}}=\frac{d_{2}^{2}-d^{2}}{d_{2}^{2}-d_{1}^{2}}=0.8
$$

Face pressure:

$$
p=p_{l}+p_{j}\left(\mathrm{~K}_{\text {out }}-\lambda\right)=0.3+2.8 \times(0.8-0.7)=0.58 \mathrm{MPa}
$$




\subsubsection{Calculate pv and Check Out}

The average velocity of the end surface:

$$
\begin{aligned}
& v=\frac{\pi n\left(\mathrm{~d}_{1}+\mathrm{d}_{2}\right) / 2}{60}=8.8 \mathrm{~m} / \mathrm{s} \\
& p v=0.58 \times 8.8=5.1 \mathrm{MPa} \cdot \mathrm{m} / \mathrm{s}<[p v]
\end{aligned}
$$

Therefore mechanical seal meets the requirements.

\section{THE DESIGN OF CENTRIFUGAL PUMP}

\subsection{Main Parameters and Design Requirements of}

\section{Pumps}

(1) $\mathrm{LiftH}=40 \mathrm{~m}$;

(2) Traffic $q=100 \mathrm{~m}^{3} / \mathrm{h}$;

(3) The necessary cavitation margin of the pump ${ }_{N P S H}=3 \mathrm{~m}$;

(4) Speed $n=2900 \mathrm{r} / \mathrm{min}$;

(5) The working medium is clear water, and $p=1000 \mathrm{~kg} / \mathrm{m}^{3}$;

(6) Working environment $0 \sim 80^{\circ}$.

\subsection{Main Parameter Determination}

\subsubsection{Determine Pump Inlet and Outlet Diameter}

(1) The inlet diameter of the pump is also called pump suction diameter, which refers to the pipe diameter of the pump suction flange. The suction diameter is determined by the inlet velocity. The inlet velocity of the pump is generally $1 \sim 3 \mathrm{~m} / \mathrm{s}$.

In terms of manufacturing and economic considerations, large pumps have a large flow velocity. In order to reduce the volume of the pump, it also improves the over-current capacity of the pump. Considering the cavitation performance, the larger inlet diameter should be taken to reduce the flow rate.

The pump with high demand for cavitation performance can be imported when the inlet diameter is less than $250 \mathrm{~mm}$. When the inlet diameter is greater than $250 \mathrm{~mm}$, the inlet velocity is desirable. Suspension centrifugal pump is used in this design.

Table 1: relationship between pump suction diameter and flow rate and flow $\mathrm{q}$

\begin{tabular}{|l|l|l|l|l|l|l|l|l|l|}
\hline \multicolumn{2}{|l|}{ Suction diameter/mm } & 40 & 50 & 65 & 80 & 100 & 150 & 200 & 250 \\
\hline $\begin{array}{l}\text { Single- } \\
\text { stage pump }\end{array}$ & $\begin{array}{l}\text { velocity/m } \\
\mathrm{m}\end{array}$ & 1.375 & 1.77 & 2.1 & 2.76 & $\begin{array}{l}3.5 \\
3\end{array}$ & 2.83 & 2.65 & 2.83 \\
\cline { 2 - 9 } & traffic/mm & 6.25 & 12.5 & 25 & 50 & 100 & 180 & 300 & 500 \\
\hline
\end{tabular}

According to the flow $q=100 \mathrm{~m}^{3} / \mathrm{h}$, refer to Table 1 , and the flow rate is $c_{s}=2.2 \mathrm{~m} / \mathrm{s}$,

$$
D_{s}=\sqrt{\frac{4 q}{c_{s} \pi}}=\sqrt{\frac{4 \times 100 / 3600}{2.2 \times \pi}}=0.1268 \mathrm{~m}
$$

Refer to pipe standard diameter, take $D_{s}=125 \mathrm{~mm}$.

(2) The outlet diameter of the pump is also called pump discharge diameter, which is the inner diameter of the pipe of the pump discharge flange. For the pump with lower lift, the outlet diameter can be the same as the suction diameter; And for the pump with higher lift, to reduce the volume of the pump and the diameter of the outlet pipe, it is advisable to take the outlet diameter less than the suction diameter

exit diameter $D_{d}=(0.7 \sim 1) D_{s}=(0.7 \sim 1) \times 125=87.5 \sim 125 \mathrm{~mm}$. take $D_{d}=100 \mathrm{~mm}$.

(3) Speed of import and export

$$
\begin{gathered}
c_{s}=\frac{4 q}{D_{s}^{2} \pi}=\frac{4 \times 100 / 3600}{0.125^{2} \times \pi}=2.26 \mathrm{~m} / \mathrm{s} \\
c_{d}=\frac{4 q}{D_{d}^{2} \pi}=\frac{4 \times 100 / 3600}{0.1^{2} \times \pi}=3.54 \mathrm{~m} / \mathrm{s}
\end{gathered}
$$

\subsubsection{Cavitation Calculation}

$$
C=\frac{5.26 n \sqrt{q}}{N P S H_{r}^{\frac{3}{4}}}=\frac{5.26 \times 2900 \times \sqrt{100 / 3600}}{3^{\frac{3}{4}}}=1115
$$

\subsubsection{Specific Speed Calculation}

Specific $\operatorname{speed}_{n_{s}}$

$$
n_{s}=\frac{3.65 n \sqrt{q}}{\mathrm{H}^{\frac{3}{4}}}=\frac{3.65 \times 2900 \times \sqrt{100 / 3600}}{40^{\frac{3}{4}}}=110.9
$$

The integer is generally taken as the speed, $n_{s}=110$. 


\subsection{Determine the Efficiency of the Pump}

The efficiency of the pump is estimated by empirical formula.

(1) Volumetric efficiency

$$
\eta_{v}=\frac{1}{1+0.68 n_{\mathrm{s}}^{-\frac{2}{3}}}=\frac{1}{1+0.68 \times 110^{-\frac{2}{3}}}=0.971
$$

(2) The efficiency of hydraulic

$$
\eta_{h}=1+0.0835 \lg \sqrt[3]{\frac{q}{n}}=1+0.0835 \lg \sqrt[3]{\frac{100 / 3600}{2900}}=0.86
$$

(3) Mechanical efficiency

Disk friction loss efficiency

$$
\eta_{m}^{\prime}=1-0.07 \frac{1}{\left(\frac{n_{s}}{100}\right)^{7 / 6}}=1-0.07 \frac{1}{\left(\frac{110}{100}\right)^{7 / 6}}=0.938
$$

Assume the bearing loss is $2 \%$, mechanicalefficiency $\eta_{m}=0.938 \times 0.98=0.919$.

(4) Total pump efficiency

$$
\eta=\eta_{m} \eta_{v} \eta_{h}=0.919 \times 0.971 \times 0.86=0.767
$$

\subsection{The Pump Shaft Power}

(1)The pump shaft power

$$
P=\frac{p \mathrm{~g} q \mathrm{H}}{1000 \eta}=\frac{1000 \times 9.8 \times 100 \times 40}{1000 \times 0.767 \times 3600}=14.20 \mathrm{~kW}
$$

The theory of lift

$$
H_{t}=\frac{\mathrm{H}}{\eta_{h}}=\frac{40}{0.86}=46.5 \mathrm{~m}
$$

The theory of traffic

$$
q_{t}=\frac{q}{\eta_{v}}=\frac{100}{0.971}=103 \mathrm{~m}^{3} / \mathrm{h}
$$

(2) The calculation power of the pump

$$
P^{\prime}=\mathrm{K} P=1.2 \times 14.2=17.0 \mathrm{~kW}
$$

$\mathrm{K}$-Water pump lift tolerance coefficient, $\mathrm{K}=1.05 \sim 1.2$;

\section{THE SEALING OF THE PUMP}

Due to the pressure difference between the fluid in the pump and the atmosphere, the pump will leak out between the shaft and the pump body during the work, so the sealing device needs to be set, which is called the shaft seal. Mechanical seals and packing seals are commonly used in sealing devices. Mechanical seals are used here.

Mechanical seal is to rely on a pair or several relative sliding face perpendicular to the axis, under the effect of fluid pressure and compensation mechanism of elastic to keep fit, and combined with auxiliary seal so as to realize seal device. The main function is to prevent the leakage of high pressure liquid from the pump, and prevent air from entering the pump, which affects the sealing performance. Although it occupies a small proportion in the centrifugal pump, the normal operation of the pump is closely related to it.

Mechanical seal is mainly composed of dynamic ring, static ring, compression element (spring) and sealing element (seal ring). As shown in Fig. 2:

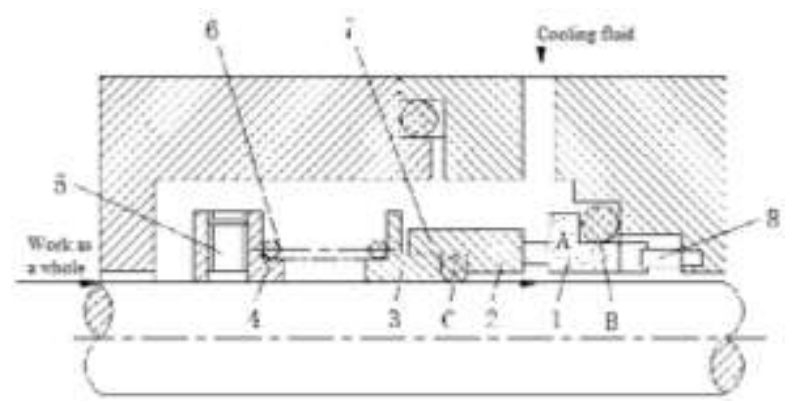

Fig 2: schematic diagram of sealing device for suspension centrifugal pump

1. Static ring; 2. moving ring; 3. moving ring seat; 4. spring seat; 5. fixed screw; 6. spring; 7. sealing ring; 8. prevent resale.

The sealing element has the sealing effect, also has the impact and the buffer vibration function.

Because of the mechanical seal structure more types, no longer enumerated. This is a suspension type centrifugal pump, so it adopts the single end surface to install the balance mechanical seal.

\section{CONCLUSION}

(1) based on the centrifugal pump seal method based on the end surface ratio pressure control, the seal of the pump was designed and improved, and the relationship between the end surface ratio pressure and each parameter was calculated and calculated.

(2) the design makes the principle and structure of mechanical seal more reasonable, its sealing performance and service life are improved, which greatly improves the efficiency of centrifugal pump and has certain reference value. 


\section{REFERENCES}

[1] Guan Xing Yan. “The modern pump technology manual,” in Astronautical Publishing House., 2011.

[2] Steve Graham. "Low life-cycle cost centrifugal pumps for utility application," World Pumps.,vol. 1, no. 484, pp. 30-33, 2007.

[3] Yao Cui Cui, etc. "The relationship between the pressure and deformation of the static ring end surface of mechanical seal rubber," in Qingdao University of Technology., 2015.

[4] Yao Cui Cui. "Study on the mechanical seal end of the ship's tail shaft and its influence on the sealing performance, " in Qingdao University of Technology., 2014.

[5] Chen Li De. "Basic course design of mechanical design," Advanced Education Publishing House., 2006.

[6] Hong Xian Zhi, Dong Zong Yu, Gu Yong Quan. “ The analytical calculation of force deformation of mechanical seal end face," Chemical Design., vol. 2, pp. 37-39, 2002.

[7] Xie Li Jing. " Sewerage improvement pump mechanical seal reconstruction, " General Machinery., vol. 2 pp. 65-68, 2004.

[8] Wang Pei Li. "The discussion of mechanical seal face ratio formula," Mechanical., vol. 27, pp. 116119, 2002.

[9] Hawthorne WR, Tan CS, Wang C, McCune JE. “ Theory of Blade Design for Large Deflections: Part I-Two Dimensional Cascades," ASME Journal of Engineering for Gas Turbines and Power., pp. 346353, 1984.

[10] Suhane, A. "Experimental Study on Centrifugal Pump to Determine the Effect of Radial Clearance on Pressure Pulsations Vibrations and Noise, ' International Journal of Engineering Research and Applications (IJERA)., vol. 2, pp. 1823-1829, 2012. 